\title{
The efficacy and safety of Apatinib combined with TACE in the treatment of hepatocellular carcinoma: a meta-analysis
}

\author{
Anan Gong ${ }^{1}$ and Xiaofei Li ${ }^{2 *}$
}

\begin{abstract}
Background: The timely and effective treatments are vital to the prognosis of patients with hepatocellular carcinoma, and the role of Apatinib combined with TACE in the treatment of hepatocellular carcinoma remains unclear. Therefore, we aimed to conduct a systematic review and meta-analysis to evaluate the efficacy and safety of Apatinib combined with transcatheter arterial chemoembolization (TACE) in the treatment of hepatocellular carcinoma.

Methods: We searched for randomized controlled trials (RCTs) on Apatinib and TACE use in the treatment of hepatocellular carcinoma. Cochrane Central Register of Controlled Trials, Embase, PubMed, China Biomedical Literature Database, China Knowledge Network, Wanfang Database, and Weipu Chinese Science and Technology Journal Database were searched up to 16 April 2021. Two researchers independently screened the literature and extracted data according to the inclusion and exclusion criteria. RevMan 5.3 software was used for Meta-analysis. This meta-analysis protocol had been registered online (available at: https://inplasy.com/inplasy-2021-6-0047/).

Results: A total of 14 RCTs involving 936 hepatocellular carcinoma patients were included. The objective remission rate $(\mathrm{OR}=2.93,95 \% \mathrm{Cl} 2.17-3.95), 1$-year survival $(\mathrm{OR}=2.47,95 \% \mathrm{Cl} 1.65-3.68), 2$-year survival $(\mathrm{OR}=2.67,95 \% \mathrm{Cl}$ 1.41-5.04), the incidence of hand-foot syndrome $(\mathrm{OR}=32.09,95 \% \mathrm{Cl} 10.87-94.74)$ and the incidence of proteinuria $(\mathrm{OR}=14.79,95 \% \mathrm{Cl}$ 6.07-36.06) of the Apatinib + TACE group was significantly higher than that of the TACE group (all $P<0.05)$. There were no significant differences in the incidence of myelosuppression ( $\mathrm{OR}=1.01,95 \% \mathrm{Cl} 0.61-1.67)$, the incidence of hypertension ( $\mathrm{OR}=7.56,95 \% \mathrm{Cl} 0.95-1.67, P=60.17)$ between Apatinib + TACE and TACE group (all $P>0.05)$.
\end{abstract}

Conclusions: Apatinib combined with TACE is more effective than TACE alone in the treatment of hepatocellular carcinoma, but it has certain adverse reactions.

Keywords: Apatinib, TACE, Liver, Cancer, Treatment, Effect, Safety, Review

\section{Introduction}

At present, hepatocellular carcinoma is the sixth commonly-seen malignant cancer in the world, and its mortality ranks fourth amongst all cancers in the world [1]. In China, the number of new cases of hepatocellular

\footnotetext{
*Correspondence: yqeh1003315698@163.com

2 Department of Infectious Diseases, YiWu Central Hospital, No. 519 Nan men Street, Yiwu, Zhejiang 322000, China
}

Full list of author information is available at the end of the article carcinoma accounts for about half of the world, and there are about 1 million new hepatocellular carcinoma patients every year [2]. Meanwhile, the patients with hepatocellular carcinoma are getting younger and younger, which seriously endangers human health $[3,4]$. Due to the lack of early diagnosis and treatments, the disease progresses rapidly and the prognosis of patients with hepatocellular carcinoma is usually poor [5]. Hepatocellular carcinoma has become a major cause of cancerassociated death. It is reported that only $20 \%$ of patients 
are eligible for surgical resection, and the long-term effect is not satisfactory, and the 5-year survival rate is not high [6]. Therefore, the early detection and treatment of hepatocellular carcinoma are essential to the prognosis of patients [7].

Transcatheter arterial chemoembolization (TACE) is a non-surgical treatment for advanced hepatocellular carcinoma [8]. TACE has the advantages of small trauma and high targeting, it can significantly inhibit the progression of tumor tissue, and its short-term effect is obvious [9]. TACE treatment of hepatocellular carcinoma creates a nutrient-deficient environment for tumor cells [10]. Chemotherapy drugs and iodized oil embolization emulsion reach the tumor blood vessels, but hypoxia is an important factor that stimulates the growth of vascular endothelial growth factor (VEGF), so hepatocellular carcinoma recurs and metastasis are rapid [11]. It's been reported that the objective remission rate is only $10-20 \%$ after TACE, and cancers are prone to recurrence and metastasis, leading to unsatisfactory therapeutic effects $[12,13]$. Therefore, it is necessary to evaluate TACE combined with various other methods to inhibit angiogenesis, in order to improve the curative effect of hepatocellular carcinoma and delay the progression of cancers.

Apatinib is a new type of molecularly targeted antiangiogenic drug that can selectively inhibit VEGF receptor 2 to inhibit tumor blood vessel growth and produce anti-tumor function [14]. Apatinib has been applied to the treatment of gastric cancer, breast cancer and other cancers [15-17]. In addition, a phase II clinical study of hepatocellular carcinoma has confirmed the efficacy of Apatinib on hepatocellular carcinoma [18]. Studies $[19,20]$ have reported that Apatinib can significantly improve the objective remission rate of patients with hepatocellular carcinoma, but there is no relevant systematic review on the role of combined use of Apatinib and TACE. Therefore, we aimed to conduct a metaanalysis of the safety and effectiveness of randomized controlled trial (RCTs) on the application of Apatinib and TACE in the treatment of hepatocellular carcinoma, to elucidate the role of Apatinib and TACE use, and to provide evidence for the treatment of hepatocellular carcinoma. We conducted this meta-analysis according to the PICOS principle of the Cochrane Collaboration. The question framework for this meta-analysis was as following. $\mathrm{P}$ (patient): patients with hepatocellular carcinoma. I(intervention): application of Apatinib and TACE in the treatment of hepatocellular carcinoma; $\mathrm{C}$ (control): application of TACE in the treatment of hepatocellular carcinoma; $\mathrm{O}$ (outcomes): objective remission rate, survival rate and related treatment complications; S(study design):RCT. This meta-analysis protocol had been registered online (available at: https://inpla sy.com/inplasy-2021-6-0047/) with registered number: INPLASY202160047.

\section{Methods \\ Literature search strategy}

We combined the subject word and free word to search the PubMed, Embase, Cochrane library, China Biomedical Literature Database, China Knowledge Network, Wanfang Database, and Weipu Chinese Science and Technology Journal Database. Besides, we searched clinical trials (https://clinicaltrials.gov/) and Chinese Trial Database (http://www.chictr.org.cn/abouten. aspx) for some unpublished data. The search time limit was from the inception to 16 April 162021 . The search strategies were as following: ("Neoplasms" OR "Hepatic" OR "Neoplasms" OR "Liver" OR "Liver Neoplasm" OR "Neoplasm" OR "Liver" OR "Hepatic Neoplasm" OR "Hepatocellular Cancers") AND ("Apatinib") AND ("Transcatheter arterial chemoembolization" OR "TACE" OR "Hepatic arterial chemoembolization"), we revised the strategies according to the characteristics of databases (see the supplementary Table 1 for more details). The language we screened was limited to English and Chinese language in this present meta-analysis.

\section{Inclusion and exclusion criteria}

The inclusion criteria of this study were the type of study design was RCT, and the populations of the study are patients diagnosed with hepatocellular carcinoma by pathological examination. The control group was treated with TACE, and the experimental group was treated with Apatinib in combination with TACE. The dosage and period of Apatinib administration were not limited. Outcome indicators such as objective remission rate, 1-year, 2-year survival, and related treatment complications were reported. The exclusion criteria of the present meta-analysis were literature review articles, animal studies, case reports, and observational studies were excluded. And we excluded the reports that did not provide detailed postoperative indicators, duplicate articles studies involving patients with malignancies other than hepatocellular carcinoma.

\section{Quality evaluation and bias risk assessment of included studies}

Two researchers independently screened the literature and extracted data. If there was any disagreement during the process, discussions were conducted for consensus, and third-party opinions would be sought if necessary. We would contact the corresponding author for missing information. The included RCTs were analyzed according to the Bias Risk Evaluation Tool of Cochrane Handbook for Systematic Reviews [21]. This tool evaluated seven 
specific domains, including: sequence generation, allocation concealment, blinding of participants and personnel, blinding of outcome assessment, incomplete outcome data, selective outcome reporting, and other issues. Each domain could be classified as low risk of bias, high risk of bias or unclear risk of bias based on related judgment criteria.

\section{Data collection}

Two authors independently collected following information: author name, year of publications, sample size, characteristics of included patients, details of intervention, outcome indicators, and the main conclusions. The primary outcome observed in this meta-analysis was objective remission rate, which was the complete disappearance of all target lesions or the sum of the diameters of all measurable target lesions is lower than the baseline by $\geq 30 \%$. The secondary outcome indicators were 1-year, 2-year survival, and related treatment complications including incidence of hand-foot syndrome, proteinuria, myelosuppression, and hypertension.

\section{Statistical methods}

The related data was extracted and sorted out, and the RevMan 5.3 software was used for meta-analysis. We used $x^{2}$ test to analyze and evaluate the heterogeneity of the results. If there was no heterogeneity between the data of each group $\left(P>0.1, I^{2}<50 \%\right)$, then we used the fixed effects model to analyze the data; If the heterogeneity was significant $\left(P \leq 0.1, I^{2} \geq 50 \%\right.$, we firstly identified the potential source of the heterogeneity, and after excluding the influence of obvious clinical heterogeneity, a random effects model was used for meta-analysis. Publication bias was evaluated by using funnel plots, and asymmetry was assessed by conducting Egger regression test. For funnel plot asymmetry, $P<.1$ was considered as significantly different.

\section{Results}

\section{Literature search results}

A total of 116 reports were retrieved from the initial search, and after screening layer by layer, 14 RCTs [22-35] were finally included. The study selection process was indicated in Fig. 1.

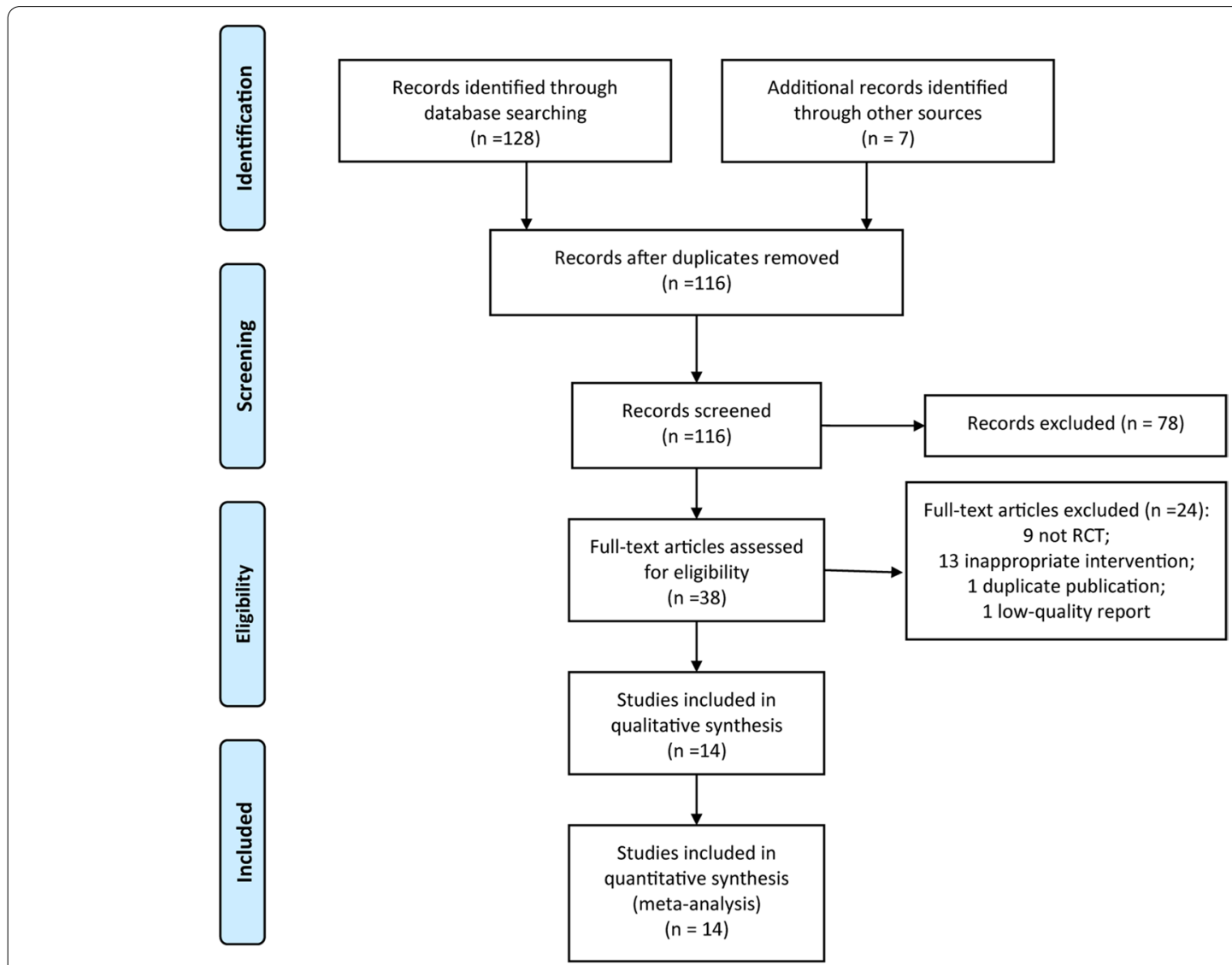

Fig. 1 PRISMA flow diagram for study selection 
Table 1 The characteristics of included studies

\begin{tabular}{|c|c|c|c|c|c|c|c|c|c|}
\hline \multirow[t]{2}{*}{ Studies } & \multicolumn{2}{|l|}{ Cases } & \multirow{2}{*}{$\begin{array}{l}\text { Type of } \\
\text { hepatocellular } \\
\text { carcinoma }\end{array}$} & \multirow{2}{*}{$\begin{array}{l}\text { Stage of hepatocellular } \\
\text { carcinoma(Edmonson } \\
\text { tumor grades) }\end{array}$} & \multicolumn{2}{|l|}{ Age } & \multicolumn{3}{|c|}{ Intervention } \\
\hline & $\begin{array}{l}\text { Apatinib } \\
+ \text { TACE } \\
\text { group }\end{array}$ & $\begin{array}{l}\text { TACE } \\
\text { group }\end{array}$ & & & $\begin{array}{l}\text { Apatinib } \\
\text { +TACE group }\end{array}$ & TACE group & $\begin{array}{l}\text { Apatinib } \\
+ \text { TACE } \\
\text { group }\end{array}$ & $\begin{array}{l}\text { TACE } \\
\text { group }\end{array}$ & $\begin{array}{l}\text { Durations of } \\
\text { intervention(months) }\end{array}$ \\
\hline $\begin{array}{l}\text { Bai } 2018 \\
{[36]}\end{array}$ & 25 & 25 & SHCC & $\|\sim\|$ & $58.34 \pm 5.67$ & $59.22 \pm 5.17$ & $\begin{array}{l}\text { Apatinib } \\
500 \mathrm{mg} / \mathrm{d} \\
+ \text { TACE } \\
\text { group }\end{array}$ & TACE & 3 \\
\hline $\begin{array}{l}\operatorname{Jin} 2017 \\
{[37]}\end{array}$ & 20 & 22 & SHCC & $\| \sim \mid V$ & $\begin{array}{l}55.24 \pm 1 \\
0.64\end{array}$ & $\begin{array}{l}54.12 \pm 1 \\
1.48\end{array}$ & $\begin{array}{l}\text { Apatinib } \\
500 \mathrm{mg} / \mathrm{d} \\
+ \text { TACE } \\
\text { group }\end{array}$ & TACE & 3 \\
\hline $\begin{array}{l}\text { Li } 2018 \\
{[38]}\end{array}$ & 54 & 52 & SHCC & $\|\sim\|$ & $53.93 \pm 5.12$ & $55.20 \pm 5.25$ & $\begin{array}{l}\text { Apatinib } \\
500 \mathrm{mg} / \mathrm{d} \\
+ \text { TACE } \\
\text { group }\end{array}$ & TACE & 6 \\
\hline $\begin{array}{l}\text { Lu } 2019 \\
\text { [39] }\end{array}$ & 22 & 21 & SHCC & $\|\sim\|$ & $58.93 \pm 9.38$ & $56.41 \pm 10.79$ & $\begin{array}{l}\text { Apatinib } \\
500 \mathrm{mg} / \mathrm{d} \\
+ \text { TACE } \\
\text { group }\end{array}$ & TACE & 3 \\
\hline $\begin{array}{l}\text { Wang } \\
2017[40]\end{array}$ & 43 & 43 & SHCC & $\|\sim\|$ & $58.28 \pm 5.21$ & $58.29 \pm 5.22$ & $\begin{array}{l}\text { Apatinib } \\
500 \mathrm{mg} / \mathrm{d} \\
+ \text { TACE } \\
\text { group }\end{array}$ & TACE & 3 \\
\hline $\begin{array}{l}\text { Wu } 2019 \\
{[41]}\end{array}$ & 28 & 31 & SHCC & $\|\sim\|$ & $55.93 \pm 11.04$ & $56.9 \pm 10.19$ & $\begin{array}{l}\text { Apatinib } \\
500 \mathrm{mg} / \mathrm{d} \\
+ \text { TACE } \\
\text { group }\end{array}$ & TACE & 3 \\
\hline $\begin{array}{l}\text { Zeng } \\
2018 \text { [42] }\end{array}$ & 38 & 38 & SHCC & NA & $56.26 \pm 4.18$ & $56.48 \pm 3.85$ & $\begin{array}{l}\text { Apatinib } \\
850 \mathrm{mg} / \mathrm{d} \\
+ \text { TACE } \\
\text { group }\end{array}$ & TACE & 3 \\
\hline $\begin{array}{l}\text { Huang } \\
2018 \text { [43] }\end{array}$ & 30 & 30 & SHCC & $|\sim|||$ & $52.45 \pm 9.12$ & $52.22 \pm 9.47$ & $\begin{array}{l}\text { Apatinib } \\
850 \mathrm{mg} / \mathrm{d} \\
+ \text { TACE } \\
\text { group }\end{array}$ & TACE & 6 \\
\hline $\begin{array}{l}\text { Xie } 2019 \\
{[44]}\end{array}$ & 42 & 50 & SHCC & NA & $53.56 \pm 9.16$ & $52.98 \pm 9.24$ & $\begin{array}{l}\text { Apatinib } \\
250 \mathrm{mg} / \mathrm{d} \\
+ \text { TACE } \\
\text { group }\end{array}$ & TACE & 3 \\
\hline $\begin{array}{l}\text { Cui } 2019 \\
{[45]}\end{array}$ & 25 & 25 & SHCC & $\|\sim\| V$ & $51.62 \pm 9.64$ & $52.24 \pm 9.88$ & $\begin{array}{l}\text { Apatinib } \\
500 \mathrm{mg} / \mathrm{d} \\
+ \text { TACE } \\
\text { group }\end{array}$ & TACE & 3 \\
\hline $\begin{array}{l}\text { Huang } \\
2017 \text { [46] }\end{array}$ & 38 & 38 & SHCC & $\|\sim\|$ & $53.09 \pm 10.42$ & $52.91 \pm 9.26$ & $\begin{array}{l}\text { Apatinib } \\
850 \mathrm{mg} / \mathrm{d} \\
+ \text { TACE } \\
\text { group }\end{array}$ & TACE & 3 \\
\hline $\begin{array}{l}\text { Wu } 2018 \\
{[47]}\end{array}$ & 28 & 28 & SHCC & $\|\sim\|$ & $52.11 \pm 10.25$ & $52.42 \pm 10.71$ & $\begin{array}{l}\text { Apatinib } \\
500 \mathrm{mg} / \mathrm{d} \\
+ \text { TACE } \\
\text { group }\end{array}$ & TACE & 3 \\
\hline $\begin{array}{l}\text { He } 2018 \\
{[48]}\end{array}$ & 50 & 50 & SHCC & $\|\sim\|$ & $52.14 \pm 9.17$ & $55.37 \pm 10.33$ & $\begin{array}{l}\text { Apatinib } \\
400 \mathrm{mg} / \mathrm{d} \\
+ \text { TACE } \\
\text { group }\end{array}$ & TACE & 3 \\
\hline $\begin{array}{l}\text { Li } 2017 \\
{[49]}\end{array}$ & 20 & 20 & SHCC & $\| \sim \mid V$ & $49.17 \pm 10.27$ & $51.06 \pm 10.12$ & $\begin{array}{l}\text { Apatinib } \\
850 \mathrm{mg} / \mathrm{d} \\
+ \text { TACE } \\
\text { group }\end{array}$ & TACE & 3 \\
\hline
\end{tabular}




\section{The characteristics of included RCTs}

Amongst the 14 included RCTs, a total of 936 patients with hepatocellular carcinoma were involved, with 463 patients received Apatinib and TACE treatment, 473 patients received TACE treatment. As presented in Table 1, all the included studies were reported from China. The dose of Apatinib ranged from $250 \mathrm{mg} /$ day to $850 \mathrm{mg} /$ day amongst RCTs.

\section{Quality assessment}

The risk of biases assessments were presented in Figs. 2 and 3. Among the included RCTs, nine RCTs [23, 25-27, $29-31,33,35]$ clearly stated the use of random number table method to generate the randomization (low risk), and five RCTs [22, 24, 26, 28, 32] mentioned the use of allocation concealment. For the blinding method, only four RCTs [23, 24, 33, 34] were clearly single-blind (high risk), and the rest did not clearly state the setting of the blinding method. None of the included RCTs clearly stated their blinding design on the outcome assessment. Five RCTs [26, 27, 29, 31, 35] had been rated as attrition biased with regard to the small samples and loss of follow-up of included patients. Two RCTs [23, 34] selectively reported the outcomes. No significant biases in other biases were found.

\section{Meta-analysis}

\section{Objective remission rate}

Thirteen RCTs [22, 24-35] reported the objective remission rate. There was no heterogeneity among the included 13 RCTs $\left(P=0.92, I^{2}=0 \%\right)$, and a fixed-effects model was used for synthesized analysis. The objective remission rate of the Apatinib + TACE group was significantly higher than that of the TACE group, and the difference was statistically significant $(\mathrm{OR}=2.93,95 \% \mathrm{CI} 2.17-3.95$, $P<0.001$ ) (Fig. 4A). As presented in Table 2, subgroup analyses of the objective remission rate indicated that
Apatinib + TACE treatment was beneficial to improve the objective remission rate both when Apatinib dose $\geq$ 600 or $<600 \mathrm{mg} /$ day (all $p<0.001$ ).

\section{One-year survival}

Seven RCTs [23, 25, 28, 30-32, 34] reported the 1-year survival. There was no heterogeneity among the included 7 RCTs $\left(P=0.97, I^{2}=0 \%\right)$, and a fixed-effects model was used for synthesized analysis. The 1-year survival of the Apatinib + TACE group was significantly higher than that of the TACE group, and the difference was statistically significant $(\mathrm{OR}=2.47,95 \% \mathrm{CI} 1.65-3.68, P<0.001)$ (Fig. 4B). As presented in Table 2, subgroup analyses of the 1-year survival indicated that Apatinib + TACE treatment was beneficial to improve the 1-year survival both when Apatinib dose $\geq 600$ or $<600 \mathrm{mg} /$ day (all $p<$ 0.001).

\section{Two-year survival}

Three RCTs [23, 25, 31] reported the 2-year survival. There was no heterogeneity among the included 3 RCTs $\left(P=0.86, I^{2}=0 \%\right)$, and a fixed-effects model was used for synthesized analysis. The 2-year survival of the Apatinib + TACE group was significantly higher than that of the TACE group, and the difference was statistically significant $(\mathrm{OR}=2.67,95 \%$ CI 1.41-5.04, $P=0.002)$ (Fig. 4C).

\section{The incidence of myelosuppression}

Six RCTs [23, 26, 27, 31, 33, 35] reported the incidence of myelosuppression. There was no heterogeneity among the included 6 RCTs $\left(P=0.86, I^{2}=0 \%\right)$, and a fixedeffects model was used for synthesized analysis. There was no significant difference in the incidence of myelosuppression between Apatinib + TACE and TACE group $(\mathrm{OR}=1.01,95 \%$ CI 0.61-1.67, $P=0.96)$ (Fig. 5A).

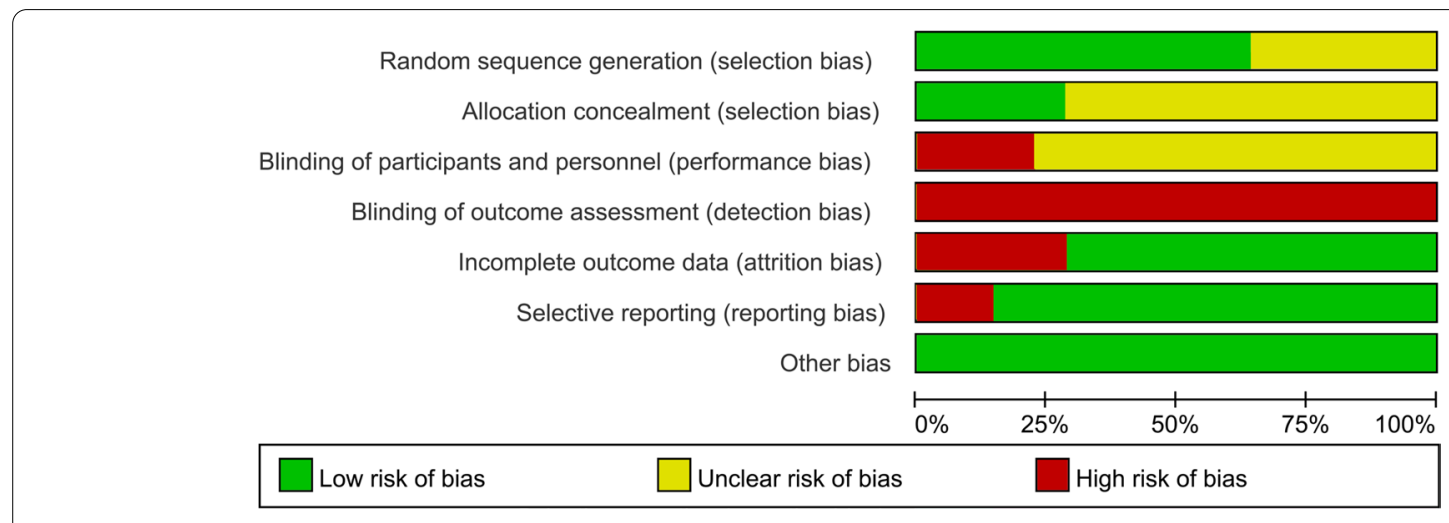

Fig. 2 Risk of bias graph 


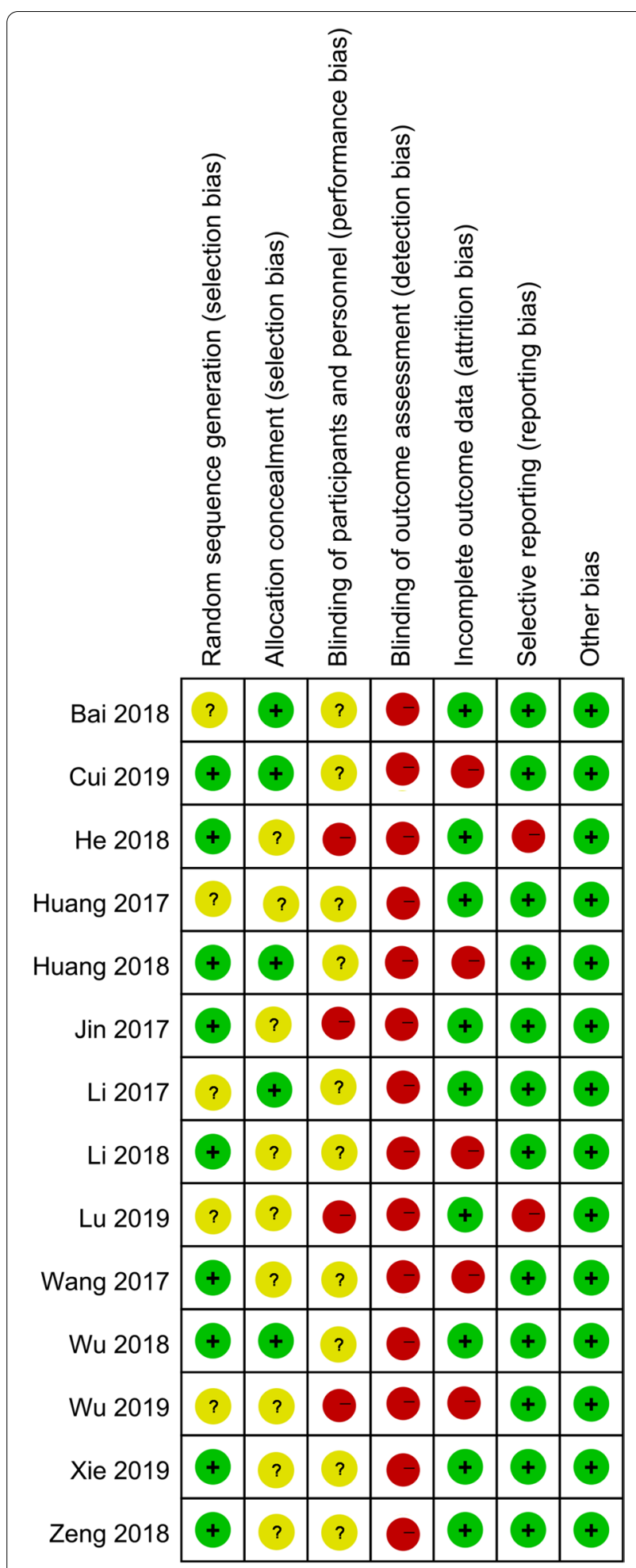

Fig. 3 Risk of bias summary

\section{The incidence of hand-foot syndrome}

Six RCTs [26, 27, 30, 31, 33, 34] reported the incidence of hand-foot syndrome. There was no heterogeneity among the included 6 RCTs $\left(P=0.56, I^{2}=0 \%\right)$, and a fixedeffects model was used for synthesized analysis. The incidence of hand-foot syndrome of the Apatinib + TACE group was significantly higher than that of the TACE group, and the difference was statistically significant (OR $=32.09,95 \%$ CI 10.87-94.74, $P<0.001$ ) (Fig. 5B).

\section{The incidence of hypertension}

Eight RCTs [23, 24, 26, 28, 30, 31, 33, 34] reported the incidence of hypertension. There was heterogeneity among the included 8 RCTs $\left(P<0.001, I^{2}=91 \%\right)$, and a random-effects model was used for synthesized analysis. There was no significant difference in the incidence of hypertension between Apatinib + TACE and TACE group $(\mathrm{OR}=7.56,95 \% \mathrm{CI} 0.95-1.67, P=60.17)$ (Fig. 5C).

\section{The incidence of proteinuria}

Five RCTs [26, 27, 31, 33, 34] reported the incidence of proteinuria. There was no heterogeneity among the included 5 RCTs $\left(P=0.56, I^{2}=11 \%\right)$, and a fixed-effects model was used for synthesized analysis. The incidence of proteinuria of the Apatinib + TACE group was significantly higher than that of the TACE group, and the difference was statistically significant $(\mathrm{OR}=14.79,95 \% \mathrm{CI}$ 6.07-36.06, $P<0.001$ ) (Fig. 5D).

\section{Publication bias}

We attempted to evaluate publication bias by using a funnel plot if 10 or more RCTs were included in an outcome meta-analysis. The funnel plot of objective remission rate (see Fig. 6) indicated that the scattered points were evenly and symmetrically distributed, suggesting that there was no publication bias.

Sensitivity analyses, which investigate the influence of 1 study on the overall risk estimate by removing study one by one, suggested that the overall risk estimates were not substantially changed by any single study. Besides, for the inconsistent result of $\mathrm{He} 2018$ in the incidence of hypertension, it might be associated to the age differences between groups, the age of patients in the TACE group was significantly higher than that of Apatinib + TACE group (55.37 \pm 10.33 vs. $52.14 \pm 9.17)$.

\section{Discussions}

With 14 RCTs included, this present meta-analysis has found that the combined use of Apatinib and TACE can significantly improve the objective remission rate, 1 -year, and 2-year survival of patients with hepatocellular carcinoma compared with TACE treatment alone; yet, the combined use of Apatinib and TACE may also increase the incidence of hand-foot syndrome and proteinuria, 


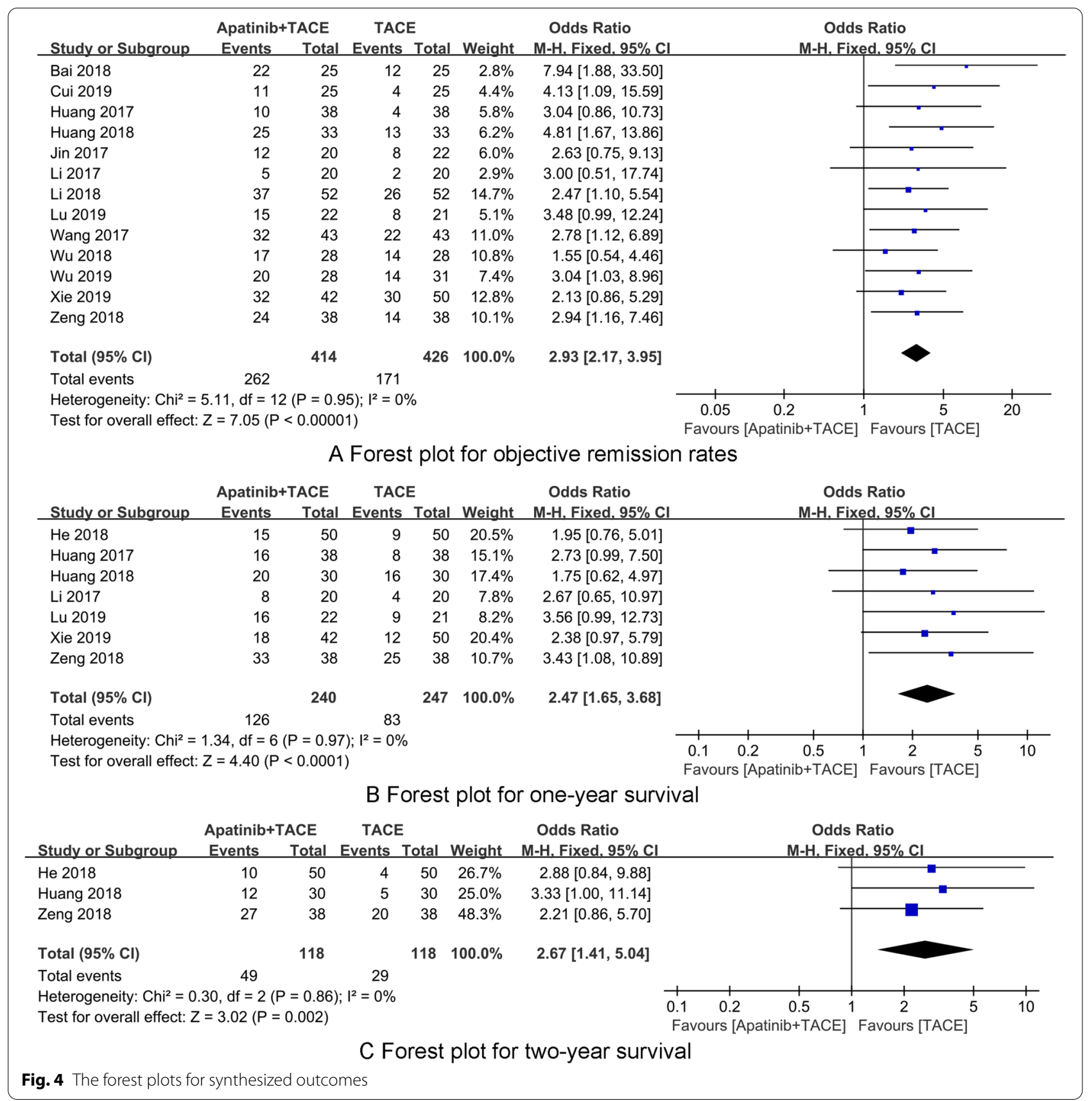

Table 2 Subgroup analyses of the objective remission rate and one-year survival based on the Apatinib dose

\begin{tabular}{|c|c|c|c|c|c|c|c|}
\hline Outcomes & Subgroups & $\begin{array}{l}\text { Number of } \\
\text { included RCTs }\end{array}$ & Heterogeneity $\left(1^{2}\right)$ & Model & OR & $95 \% \mathrm{Cl}$ & $P$ \\
\hline \multirow[t]{2}{*}{ Objective remission rat } & Apatinib dose $\geq 600 \mathrm{mg} / \mathrm{d}$ & 3 & $0 \%$ & Fixed & 2.44 & $1.97 \sim 2.81$ & $<0.001$ \\
\hline & Apatinib dose $<600$ mg/d & 10 & $0 \%$ & Fixed & 2.91 & $2.53 \sim 3.67$ & $<0.001$ \\
\hline \multirow[t]{2}{*}{ One-year survival } & Apatinib dose $\geq 600 \mathrm{mg} / \mathrm{d}$ & 2 & $0 \%$ & Fixed & 2.69 & $2.04 \sim 2.89$ & $<0.001$ \\
\hline & Apatinib dose $<600$ mg/d & 5 & $16 \%$ & Fixed & 2.17 & $1.89 \sim 2.55$ & $<0.001$ \\
\hline
\end{tabular}




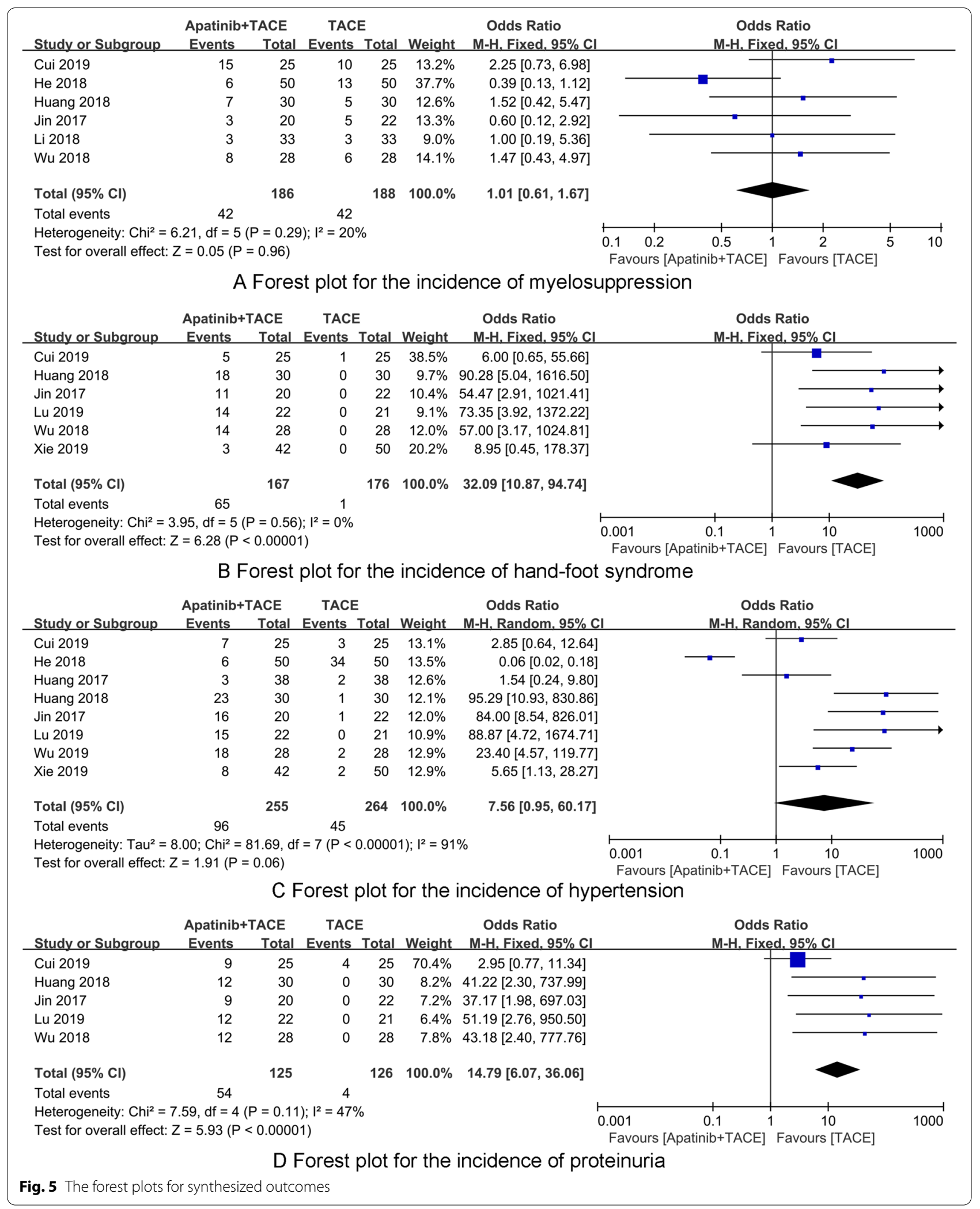




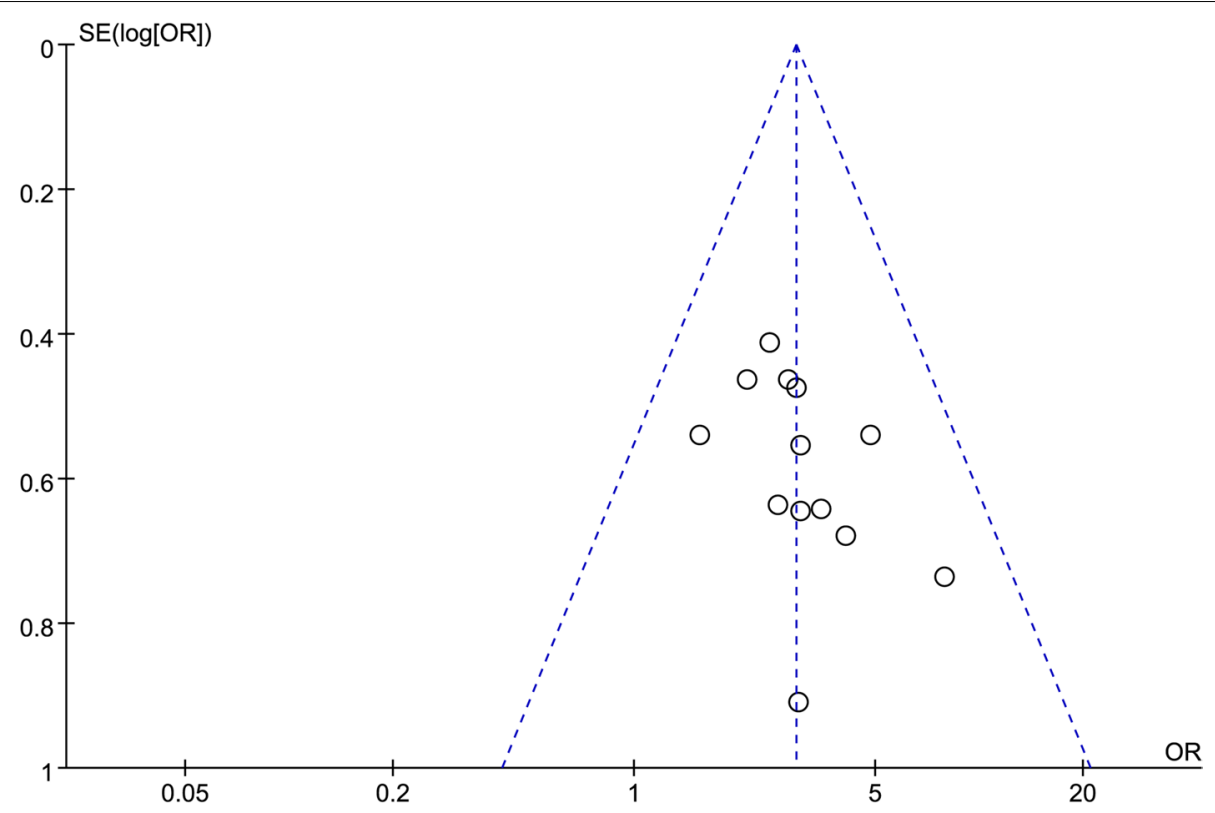

Fig. 6 Funnel plot for the objective remission rates

and there was no significant difference in the incidence of myelosuppression and hypertension. However, all blinding information are most commonly under-reported, which may lead to result biases. Therefore, the results of this present meta-analysis should be treated with cautions, and future RCTs with rigorous design and longer follow-up are warranted.

Angiogenesis is closely associated with the occurrence, development, and metastasis of malignant tumors. Tumor cells can produce a variety of molecules to induce angiogenesis, the new blood vessels can provide nutrients necessary for tumor growth and excrete metabolites [50, 51]. Additionally, tumor cells are mainly transferred to other parts of the body through vascular dissemination [18]. Therefore, inhibiting tumor angiogenesis can inhibit tumor cell growth and metastasis. Previous studies [41, 52] has shown that tumor angiogenesis is a dynamic process with multi-factors participation. The signal cascade mediated by VEGFR-2 is the key regulatory pathway, which can regulate the proliferation, migration, survival and permeability of vascular endothelial cells [53]. It is been reported [54] that Apatinib can inhibit the proliferation of a variety of hepatocellular carcinoma cells, and the inhibitory effect is positively correlated with the expression of VEGFR-2. Apatinib can also affect the expression of cell cycle regulating point proteins, which in turn changes the cell cycle.

Apatinib is also an anti-angiogenesis molecular targeted drug, which by highly specific inhibition of the activity of the VEGFR-2 tyrosine kinase pathway, while blocking the signal transduction pathway after VEGF and its receptor are combined, it has been used for secondline treatment of gastric cancer [55]. It is been found that $60 \mu \mathrm{g} / \mathrm{ml}$ is the optimal concentration of Apatinib for radiotherapy in gastric cancer cells [56]. Apatinib combined with radiotherapy can reduce the negative effects of radiotherapy and reduce cancer-associated mortality [57]. However, there are also shortcomings in the biological treatment process. Skin inflammation, hypertension, gastrointestinal reactions, proteinuria, cytopenias, hand-foot syndrome, abdominal pain, and abdominal distension often occur during treatment, which can be alleviated by symptomatic supportive treatment [58]. It's been reported that Apatinib is well tolerated and very effective in the treatment of advanced HCC, and it is beneficial in terms of objective remission rate and disease control rate [59]. Previous studies [60, 61] have shown that TACE combined with Apatinib has a better mid- and long-term efficacy for the treatment of advanced hepatocellular carcinoma, and has a certain degree of safety.

This study does have the following limitations. Firstly, we only searched for the reports published in the language of English and Chinese, and the RCTs included in this meta-analysis are all from China, and the results of the study may have regional and ethics biases. Secondly, the most included studies did not mention specific random allocation methods, and most of them did not mention blinding design and allocation concealment. We have included heterogeneous regimens based on the Apatinib dose to analyze the effects of Apatinib and 
TACE treatments. Thirdly, the sample size is not large enough, and it may be underpower to detect the potential difference between groups. It is necessary to conduct higher-quality researches with rigorous design to further evaluate the role of Apatinib in the treatment of hepatocellular carcinoma in the future.

\section{Conclusions}

To sum up, the combination of Apatinib and TACE can improve the objective remission rate and 1-year and 2-year survival of patients with hepatocellular carcinoma. In terms of safety, the use of Apatinib may have higher risk of hypertension, hand-foot syndrome, and proteinuria. The occurrence of such adverse reactions should be considered in clinical applications. Still, the dosage and duration of Apatinib in the treatment of hepatocellular carcinoma has not yet been unified. It is still too early to try to make certain assumptions. In the future, largescale, high-quality clinical studies from the perspective of dosage and different populations are needed to further elucidate the effects and safety of Apatinib in the treatment of hepatocellular carcinoma.

\section{Abbreviations}

TACE: Transcatheter arterial chemoembolization; VEGF: Vascular endothelial growth factor; RCT: Randomized controlled trial; CENTRAL: Cochrane Central Register of Controlled Trials.

\section{Supplementary Information}

The online version contains supplementary material available at https://doi. org/10.1186/s12957-021-02451-8.

Additional file 1: Supplementary Table 1. Search Strategy for Each Database.

\section{Acknowledgements}

None.

\section{Authors' contributions}

$X \mathrm{~L}$ designed the research. $\mathrm{AG}$ and $\mathrm{XL}$ conducted research. $\mathrm{AG}$ and $\mathrm{XL}$ analyzed data. AG wrote the first draft of manuscript. XL had primary responsibility for final content. All authors read and approved the final manuscript.

\section{Funding}

None.

\section{Availability of data and materials}

All data generated or analyzed during this study are included in this published article.

\section{Declarations}

Ethics approval and consent to participate

Not applicable since our study is a meta-analysis

\section{Consent for publication}

Not applicable.

\section{Competing interests}

The authors declare that they have no competing interests.

\section{Author details}

${ }^{1}$ Department of Hepatobiliary Surgery, YiWu Central Hospital, No. 519 Nan men Street, Yiwu, Zhejiang 322000, China. ${ }^{2}$ Department of Infectious Diseases, YiWu Central Hospital, No. 519 Nan men Street, Yiwu, Zhejiang 322000, China.

Received: 25 Auqust 2021 Accepted: 22 November 2021

Published online: 04 March 2022

\section{References}

1. Kim YJ, Jang H, Lee K, Park S, Min SG, Hong C, et al. PAIP 2019: liver cancer segmentation challenge. Med Image Anal. 2021;67:101854.

2. Zhou M, Wang H, Zeng X, Yin P, Zhu J, Chen W, et al. Mortality, morbidity, and risk factors in China and its provinces, 1990-2017: a systematic analysis for the global burden of disease study 2017. Lancet. 2019;394(10204):1145-58.

3. Global Burden of Disease Liver Cancer C, Akinyemiju T, Abera S, Ahmed M, Alam N, Alemayohu MA, et al. The burden of primary liver cancer and underlying etiologies from 1990 to 2015 at the global, regional, and National Level: results from the global burden of disease study. JAMA Oncol 2017. 2015;3(12):1683-91.

4. Sakuraoka Y, Kubota K, Tanaka G, Shimizu T, Tago K, Park KH, et al. Is left-sided involvement of hepatocellular carcinoma an important preoperative predictive factor of poor outcome? World J Surg Oncol. 2020;18(1):317.

5. Pan R, Zhu M, Yu C, Lv J, Guo Y, Bian Z, et al. Cancer incidence and mortality: a cohort study in China, 2008-2013. Int J Cancer. 2017; 141(7):1315-23.

6. Cao MD, Wang H, Shi JF, Bai FZ, Cao MM, Wang YT, et al. Disease burden of liver cancer in China: an updated and integrated analysis on multi-data source evidence. Zhonghua Liu Xing Bing Xue Za Zhi. 2020;41(11):1848-58.

7. Peng W, Li C, Zhang X, Wen T, Chen Z. The impact of thrombocytopenia on prognosis of HBV-related small hepatocellular carcinoma: a propensity score matching analysis. World J Surg Oncol. 2021;19(1):46.

8. Jiang C, Cheng G, Liao M, Huang J. Individual or combined transcatheter arterial chemoembolization and radiofrequency ablation for hepatocellular carcinoma: a time-to-event meta-analysis. World J Surg Oncol. 2021;19(1):81

9. Liu K, Zhou C, Lv W, Cheng D, Lu D, Zhang Z, et al. Factors to transcatheter arterial chemoembolization liver cancer stage C. Minim Invasive Ther Allied Technol. 2020;29(1):49-55.

10. Liapi E, Geschwind JF. Transcatheter arterial chemoembolization for liver cancer: is it time to distinguish conventional from drug-eluting chemoembolization? Cardiovasc Intervent Radiol. 2011;34(1):37-49.

11. Luo X, Li Y, Shang Q, Liu H, Song L. Role of diffusional kurtosis imaging in evaluating the efficacy of transcatheter arterial chemoembolization in patients with liver cancer. Cancer Biother Radiopharm. 2019;34(10):614-20.

12. Arslan M, Degirmencioglu S. Liver abscesses after transcatheter arterial embolization. J Int Med Res. 2019;47(3):1124-30.

13. Liu A, Xu W, Xu H, Wang Y, Gu YM. Therapeutic effect of transcatheter arterial chemoembolization combined with ultrasound-guided microwave ablation for treatment of liver cancer in special sites. Zhonghua Gan Zang Bing Za Zhi. 2017;25(12):914-9.

14. Xu J, Zhang Y, Jia R, Yue C, Chang L, Liu R, et al. Anti-PD-1 antibody SHR1210 combined with apatinib for advanced hepatocellular carcinoma, gastric, or esophagogastric junction cancer: an open-label, dose escalation and expansion study. Clin Cancer Res. 2019;25(2):515-23.

15. Scott $L$. Apatinib: a review in advanced gastric cancer and other advanced cancers. Drugs. 2018;78(7):747-58.

16. Geng R, Song L, Li J, Zhao L. The safety of apatinib for the treatment of gastric cancer. Expert Opin Drug Saf. 2018;17(11):1145-50.

17. Shao F, Zhang H, Yang X, Luo X, Liu J. Adverse events and management of apatinib in patients with advanced or metastatic cancers: a review. Neoplasma. 2020;67(4):715-23. 
18. Liu X, Deng L, Guo R, Liang Q, Liu S, Hu P. Evaluation of total liver perfusion imaging of $\mathrm{CT}$ for efficacy of transcatheter arterial chemoembolization combined with apatinib on rabbit VX2 liver tumors. Zhong Nan Da Xue Xue Bao Yi Xue Ban. 2019;44(5):477-84.

19. Roviello G, Ravelli A, Fiaschi Al, Cappelletti MR, Gobbi A, Senti C, et al. Apatinib for the treatment of gastric cancer. Expert Rev Gastroenterol Hepatol. 2016;10(8):887-92.

20. Wang Y, Li W, Jing N, Meng X, Zhou S, Zhu Y, et al. Apatinib in recurrent anaplastic meningioma: a retrospective case series and systematic literature review. Cancer Biol Ther. 2020;21(7):583-9.

21. Zeng X, Zhang Y, Kwong JS, Zhang C, Li S, Sun F, et al. The methodological quality assessment tools for preclinical and clinical studies, systematic review and meta-analysis, and clinical practice guideline: a systematic review. J Evid Based Med. 2015;8(1):2-10.

22. Songtao B, Yuemeng Z. The clinical efficacy of TACE combined with apatinib on advanced liver cancer. Modern Chin Doctor. 2018;56(22):90-2 95.

23. Fan $\mathrm{H}$, Xudong $\mathrm{C}$, Zhenwen $\mathrm{L}$. Analysis of the effect of transcatheter arterial chemoembolization (TACE) combined with apatinib in patients with advanced liver cancer. Oncol Pharm. 2018;12(3):383-6.

24. Fazong W, Xiuling L, Jingjing S. Anti-hepatocarcinoma efficacy of apatinib combined with hepatic artery chemoembolization and its effect on tumor angiogenesis. J Wenzhou Med Univ. 2019;49(6):423-6 431.

25. Guangyuan Z, Gong W, Li L, Wen Z. Clinical study of apatinib tablets combined with hepatic artery chemoembolization in the treatment of advanced primary liver cancer. Chin J Clin Pharmacol. 2018;34(23):2693-6.

26. Haizhong C, Wei G, Dedong C. The effect of apatinib mesylate combined with hepatic artery embolization chemotherapy in the treatment of advanced primary liver cancer. China Medical Herald. 2019;16(14):88-91.

27. Jian W, Fang Y, Guanhong L. Effect and safety analysis of transhepatic artery chemoembolization combined with apatinib in the treatment of advanced primary liver cancer. J Clin Hepatobil Dis. 2018;34(4):775-8.

28. Jiangyuan $\mathrm{H}$, Wei H, Qiaohua Z. Application of transcatheter arterial chemoembolization combined with apatinib mesylate in advanced hepatocellular carcinoma. Chin J Hepatol. 2017;9(4):78-81.

29. Lanrong W, Xi W, Yang C. The effect of apatinib combined with arterial embolization in interventional treatment of liver cancer and its influence on vascular endothelial growth factor and apoptosis-related factors. Int Med Health Guidance News. 2017;23(7):1015-7.

30. Qingyun X, Zehua L, Feng G. Clinical efficacy analysis of apatinib mesylate combined with callispheres drug-loaded microspheres-hepatic artery chemoembolization (DEB-TACE) in the treatment of advanced hepatocellular carcinoma. J Hepatobiliary Surg. 2019;27(2):95-9.

31. Rui H, Lizheng Y, Wenhui L. Evaluation of the efficacy and safety of hepatic artery chemoembolization combined with apatinib mesylate in the treatment of advanced liver cancer. Tumor. 2018;38(10):965-72.

32. Wei L, Wenling M, Huanqing G. Clinical study of TACE combined with apatinib mesylate in the treatment of advanced liver cancer. Oncol Pharm. 2017;7(1):74-8.

33. Xinli J, Wei L. TACE combined with apatinib in the treatment of advanced hepatocellular carcinoma. Chin Intervent Imaging Ther. 2017;14(4):200-4.

34. Yang $L$, Yongneng J, Cheng $W$. The efficacy of apatinib combined with TACE in the treatment of advanced hepatocellular carcinoma. J Intervent Radiol. 2019;28(2):162-5.

35. Ying $L$, Dongyang $Y$, Xiaorong $L$. The effect of apatinib combined with TACE on AFP, VEGF and CEA in patients with liver cancer. Liver. 2018;23(5):426-30.

36. Bai S, Yuemeng Z. The clinical efficacy of TACE combined with apatinib on advanced liver cancer. Modern Chinese Doctor. 2018;56(22):90-5.

37. He F, Xudong C, Zhenwen L. Analysis of the effect of transcatheter arterial chemoembolization (TACE) combined with apatinib in patients with advanced liver cancer. Oncology Pharmacy. 2018;12(3):383-6.

38. Wu F, Xiuling $L$, Jingjing $S$. Anti-hepatocarcinoma efficacy of apatinib combined with hepatic artery chemoembolization and its effect on tumor angiogenesis. Journal of Wenzhou Medical University. 2019;49(6):423-6, 31

39. Zeng G, Gong W, li L, Wen Z. Clinical study of apatinib tablets combined with hepatic artery chemoembolization in the treatment of advanced primary liver cancer. Chinese J Clin Pharmacol. 2018;34(23):2693-6.

40. Cui H, Wei G, Dedong C. The effect of apatinib mesylate combined with hepatic artery embolization chemotherapy in the treatment of advanced primary liver cancer. China Medical Herald. 2019;16(14):88-91.
41. Wu S, Zhou J, Guo J, Hua Z, Li J, Wang Z. Apatinib inhibits tumor growth and angiogenesis in PNET models. Endocr Connect. 2019;8(1):8-19.

42. Wu J, Fang Y, Guanhong L. Effect and safety analysis of transhepatic artery chemoembolization combined with apatinib in the treatment of advanced primary liver cancer. J Clin Hepatobiliary Dis. 2018;34(4):775-8

43. Huang J, Wei H, Qiaohua Z. Application of transcatheter arterial chemoembolization combined with apatinib mesylate in advanced hepatocellular carcinoma. Chin J Hepatology. 2017;9(4):78- 81.

44. Wang $L, X i$ W, Yang $C$. The effect of apatinib combined with arterial embolization in interventional treatment of liver cancer and its influence on vascular endothelial growth factor and apoptosis-related factors. Int Med Health Guidance News. 2017;23(7):1015-7.

45. Huang R, Lizheng Y, Wenhui L. Evaluation of the efficacy and safety of hepatic artery chemoembolization combined with apatinib mesylate in the treatment of advanced liver cancer. Tumor. 2018;38(10):965-72.

46. Li W, Wenling M, Huanqing G. Clinical study of TACE combined with apatinib mesylate in the treatment of advanced liver cancer. Oncol Pharm. 2017;7(1):74-8.

47. Jin X, Wei L. TACE combined with apatinib in the treatment of advanced hepatocellular carcinoma. Chinese Interventional Imaging and Therapy. 2017;14(4):200-4.

48. Lu Y, Yongneng J, Cheng W. The efficacy of apatinib combined with TACE in the treatment of advanced hepatocellular carcinoma. J Interv Radiol. 2019;28(2):162-5

49. Li Y, Dongyang Y, Xiaorong L. The effect of apatinib combined with TACE on AFP, VEGF and CEA in patients with liver cancer. Liver. 2018;23(5):426-30.

50. Liang Q, Kong L, Du Y, Zhu X, Tian J. Antitumorigenic and antiangiogenic efficacy of apatinib in liver cancer evaluated by multimodality molecular imaging. Exp Mol Med. 2019;51(7):76.

51. Cheng Z, He L, Guo Y, Song Y, Song S, Zhang L. The combination therapy of transarterial chemoembolisation and sorafenib is the preferred palliative treatment for advanced hepatocellular carcinoma patients: a metaanalysis. World J Surg Oncol. 2020;18(1):243.

52. Jia C, Ge K, Xu S, Liu L, Weng J, Chen Y. Selective occlusion of the hepatic artery and portal vein improves liver hypertrophy for staged hepatectomy. World J Surg Oncol. 2019;17(1):167.

53. Ni Y, Ye X. Apatinib for hepatocellular carcinoma. J Cancer Res Ther. 2019;15(4):741-2.

54. Kou P, Zhang Y, Shao W, Zhu H, Zhang J, Wang H, et al. Significant efficacy and well safety of apatinib in an advanced liver cancer patient: a case report and literature review. Oncotarget. 2017:8(12):20510-5.

55. Shuanggang C, Shen L, Qiu Z, Qi H, Cao F, Xie L, et al. Transarterial chemoembolization combined with microwave ablation and apatinib in patients with Barcelona clinic liver cancer stage $C$ hepatocellular carcinoma: a propensity score matching analysis. J Cancer Res Ther. 2020;16(2):250-7.

56. Xu Y, Huang Z, Lu H, Yu X, Li Y, Li W, et al. Apatinib in patients with extensive-stage small-cell lung cancer after second-line or third-line chemotherapy: a phase II, single-arm, multicentre, prospective study. $\mathrm{Br}$ J Cancer. 2019;121(8):640-6.

57. Zhen $L$, Jiali $C$, Yong F, Han $X$, Hongming $P$, Weidong $H$. The efficacy and safety of apatinib treatment for patients with unresectable or relapsed liver cancer: a retrospective study. J Cancer. 2018:9(16):2773-7.

58. Zhang XD, Li YH, Chen DX, You WW, Hu XX, Chen BB, et al. The effect of apatinib on pharmacokinetic profile of buspirone both in vivo and in vitro. J Pharm Pharmacol. 2020;72(10):1405-11.

59. Zhao L, Yang Y, Gao Q. Efficacy and safety of nivolumab plus apatinib in advanced liver carcinosarcoma: a case report. Immunotherapy. 2019;11(8):651-6.

60. Liu J, Xie S, Duan X, Chen J, Zhou X, Li Y, et al. Assessment of efficacy and safety of the transcatheter arterial chemoembolization with or without apatinib in the treatment of large hepatocellular carcinoma. Cancer Chemother Pharmacol. 2020;85(1):69-76.

61. Zhou C, Yao Q, Zhang H, Guo X, Liu J, Shi Q, et al. Combining transcatheter arterial embolization with iodized oil containing Apatinib inhibits HCC growth and metastasis. Sci Rep. 2020;10(1):2964.

\section{Publisher's Note}

Springer Nature remains neutral with regard to jurisdictional claims in published maps and institutional affiliations. 